\title{
Errando para aprender: a importância dos desafios e dos fracassos para os jogos digitais na Educação
}

\author{
Bruno Henrique de Paula - brunohpaula@gmail.com \\ Prof. Dr. José Armando Valente - jvalente@ unicamp.br \\ Instituto de Artes - Universidade Estadual de Campinas (IA/UNICAMP)
}

\begin{abstract}
Resumo: Atualmente, nota-se um crescente interesse no uso de jogos digitais na Educação. Com o avanço desse tipo de iniciativa, faz-se necessário destacar a relevância educacional de dois elementos importantes encontrados nos bons jogos digitais: os desafios e, paradoxalmente, os fracassos. Para que esse potencial educacional se torne realidade, entretanto, é necessária uma mudança de mentalidade: é preciso que os erros e fracassos sejam encarados não como um resultado definitivo, mas sim como um estado transitório, passível de ser corrigido pelo próprio aluno a partir de sua reflexão e apoio do professor. A partir da reflexão baseada em diferentes trabalhos e de uma experiência prática, mostramos que, quando envolvidos em uma tarefa desafiadora e apoiados por professores ou colegas, alunos são capazes de corrigirem seus próprios equívocos a partir de reflexões e de construírem conhecimento.
\end{abstract}

Palavras-chave: jogos digitais, Educação, desafios, erros, depuração.

\section{Failing to learn: the importance of challenges and failures for digital games in Education}

\begin{abstract}
Currently, it's possible to notice an upward trend towards the use of videogames in Education. As these initiatives become more and more popular, it is necessary to remark the educational relevance of two important elements that could be found in good digital games: challenges and, paradoxically, failures. However, to fulfill this educational potential, we must move towards a mentality change: the failings and errors should be faced not as a final result, but as a transitory state, which the student could fix through reflection and external help. Through reflecting over diverse papers and a practical experience, we defend that, when involved in a challenging task and helped by teachers or colleagues, students are capable of correcting their own mistakes through reflecting and able to build knowledge.
\end{abstract}

Keywords: digital games, Education, challenges, errors, debugging.

\section{Introdução}

Os jogos digitais têm conquistado cada vez mais espaço na Educação. Estão sendo utilizados diferentes tipos de jogos - jogos "educativos", serious games, jogos comerciais (Egenfeldt-Nielsen, Smith; Tosca, 2008) - em diferentes abordagens - jogar para aprender (Klopfer, Osterweild; Salen, 2009; Squire, 2011) ou aprender através da criação de jogos por parte dos alunos (Burn; Buckingham, 2007) - para diferentes fins ensino de conteúdos regulares (Squire, 2011) ou desenvolvimento de competências cognitivas, como planejamento estratégico, criação e testes de hipóteses e solução de problemas (Buckingham, 2007). Muitas vezes, a escolha em explorar os jogos na Educação se dá por conta do engajamento que esses artefatos supostamente podem fomentar; ao entrarem em contato com dados empíricos que mostram o grande número de jovens que admitem jogarem videogames (McGonigal, 2012). Com isso, educadores 
passam a se interessar em explorar esta relação entre jogos e este público, utilizando-a no ensino.

Contudo, para que esse fator engajante dos jogos seja explorado, é preciso compreender por que motivos um jogo digital pode ser tão encantador. Muitas vezes, destaca-se a diversão como o elemento motivador responsável pelo sucesso de um jogo (Hunicke, Leblanc; Zubek, 2004). Porém, o que separa um videogame "divertido" de outro "não-divertido", e como explorar esse potencial motivador dos jogos na Educação?

Para isso, é preciso compreender os jogos como um artefato constituído por diferentes aspectos (visual, textual, sonoro, representacional, formal) igualmente importantes, que interagem entre si, dando origem a um produto mais complexo que a mera junção desses componentes, ou, em outras palavras, eles devem ser vistos como sistemas (Salen; Zimmerman, 2003). A diversão seria, portanto, um produto da interação do jogador com o sistema - o jogo em si. Desta maneira, é preciso respeitar esse fator sistêmico dos jogos, assim como utilizá-lo a favor do processo de ensino e de aprendizagem.

Em algumas situações, certas características inerentes aos jogos digitais não são respeitadas quando se tenta conceber jogos voltados especificamente à Educação, levando a um desperdício de potencial. Como exemplo, podem ser destacadas iniciativas que acabam por reduzir os videogames a versões digitalizadas de atividades do tipo exercício-e-prática, em que os jogadores apenas seguem tarefas e recebem "recompensas" (animações ou pontos, por exemplo). Esse tipo de iniciativa limita o jogo digital a cumprir um papel de incentivo à mera memorização de informações, levando ao que Papert (1985) chama de "ensino dissociado": quando o educando recebe informações, mas não recursos suficientes para compreender o que está sendo ensinado. Se esse tipo de iniciativa é limitante, que aspectos dos jogos digitais poderiam ser explorados em busca de um maior potencial pedagógico?

Uma das principais possibilidades educacionais que os jogos digitais apresentam é a de fornecer rastros ao jogador: o meio digital permite que o jogador possa salvar múltiplas sessões de jogo e revisitá-las, analisando suas decisões e os resultados obtidos, os quais, como pretendemos destacar nesse artigo, fornecem grandes oportunidades para a construção do conhecimento. Destaca-se ainda que essa é uma característica favorecida pelo suporte digital, pois em uma sessão de jogo analógico, isso é possível apenas se os jogadores realizarem registros externos (como tomarem nota das escolhas realizadas, ou ainda se a sessão de jogo for registrada em vídeo).

Contudo, é necessário ressaltar um aspecto apresentado acima que pode passar despercebido, em um primeiro momento, para se compreender como os jogos digitais podem obter sucesso na Educação. Não gratuitamente, Gee (2003) define que os bons jogos são experiências de aprendizagem. Para esse autor, um bom jogo é aquele que "prende" o jogador, que o faz sentir vontade de progredir, de explorá-lo e superá-lo. Tendo isso em mente, é possível considerar que o bom jogo é aquele que desafia o jogador, que o instiga a ir além desse desafio. Em suma, é aquele que propicia o que Papert chama de hard fun (apud Caperton, 2005), quando uma atividade é divertida porque é difícil, instigante. Temos aqui, portanto, um indício de que o desafio é uma das principais fontes da diversão em uma atividade (incluídos aqui os jogos digitais), fazendo assim com que qualquer tarefa possa se apresentar como mais estimulante.

Da dificuldade, que torna o jogo divertido, com certeza surgirão erros e fracassos por parte dos jogadores. No entanto, ao contrário do que pode parecer em um primeiro 
momento, esses resultados insatisfatórios não devem ser rejeitados ou ignorados, mas sim explorados, pois são valiosos recursos educacionais. Valente (2001) descreve o conceito de depurar - termo originário da Ciência da Computação para o processo conhecido como debugging em inglês, que nada mais é do que o processo de seguir passo a passo o código programado de modo a encontrar e corrigir falhas (bugs) - como atividade importante para a Educação. A depuração permite que o educando reflita sobre o que ocorreu a partir de suas ações e construa o conhecimento a partir dessa experiência, fazendo-o de maneira mais sólida e atingindo, assim, maiores níveis de compreensão.

De certa maneira, os termos usados para definirem os erros e fracassos carregam um sentido muito negativo, como se fossem permanentes, impossíveis de serem corrigidos e superados. Desse modo, há mais sentido encará-los como um bug, como um deslize cometido de modo involuntário que levou a um resultado indesejado, sendo essa uma situação transitória, passível de ser modificada (Valente, 2001). Assim, é preciso ter em mente que, nesse artigo, sempre que tratarmos de "erro" e "fracasso" (e outros análogos, como "equívoco", "falha", "insucesso", "derrota" etc.) nos referiremos a esses como eventos transitórios, que podem ser melhorados e corrigidos, e não como definitivos ou que devem ser punidos.

Dessa maneira, nesse trabalho, procuraremos apresentar como o desafio é um elemento fundamental para o sucesso de um jogo (seja no entretenimento, seja na Educação). Da mesma forma, mostraremos como os equívocos e insucessos que ocorrem durante um jogo não só são elementos da natureza de um videogame, como também são importantes para o engajamento e a aprendizagem. Esses objetivos serão atingidos a partir das reflexões por nós realizadas, tanto sobre diferentes trabalhos encontrados na literatura especializada quanto sobre uma experiência prática na qual os alunos foram incentivados a desenvolverem seus próprios jogos. Através desses pensamentos, mostraremos como os desafios e a depuração dos "erros" e "fracassos" (tratados como bugs) podem ser elementos importantes para a construção do conhecimento.

\section{A importância do desafio}

Papert não é o único a relacionar a diversão à qualidade do desafio apresentado. Koster (2005) também considera a diversão um elemento-chave para os jogos digitais. Contudo, esse autor adiciona outro componente em sua tentativa de explicar como a diversão emerge de um jogo: a aprendizagem. Para Koster (2005), os jogos são problemas a serem resolvidos de maneira autotélica (autoimposta), e a diversão está exatamente em encontrar as soluções para esses problemas, em compreender e dominar o desafio proposto pelo jogo. Da mesma maneira, Koster relaciona o tédio ao domínio total do desafio e, em consequência, ausência de aprendizagem. Em suas próprias palavras, os jogos "(...) são exercícios para nossos cérebros. Jogos que falham em exercitar nossos cérebros se tornam tediosos" (2005, p.38). Esta relação entre diversão e aprendizagem nos jogos digitais é conhecida como a Teoria da Diversão de Koster.

Assim, para Koster, somos movidos pelo nosso desejo de aprender; porém, quando aprendemos, e o jogo nada mais acrescenta à nossa cognição, ele deixa de ser interessante. A partir dessa visão é possível compreender como o desafio proposto por um jogo se torna um elemento crucial para manter a motivação do jogador: um jogo que não apresenta desafio é superado com facilidade e torna-se uma atividade tediosa com 
rapidez. Para exemplificar essa ideia, Koster (2005) resgata o "jogo-da-velha": depois de certo tempo jogando, todos os jogos começam a ter o mesmo resultado final, o empate. Nesse caso, os dois participantes hipotéticos dominaram completamente o jogo, que não apresenta mais nenhum padrão a ser absorvido: é o esgotamento do modelo do jogo. O desafio deixa de existir e a atividade, antes prazerosa, torna-se tediosa.

Porém, não basta imaginar que a existência de um desafio constante seja o suficiente para que o jogo seja divertido. Koster (2005) destaca como um desafio muito além da capacidade de compreensão e domínio do jogador fará com que a atividade deixe de ser divertida. Dessa maneira, para que seja engajante, um jogo deve apresentar um problema que seja complexo, mas ao mesmo tempo permitir que o jogador possua (ou construa) os meios necessários para compreendê-lo e superá-lo.

De certa maneira, é possível fazer um paralelo entre esta relação desafiohabilidade e a Zona de Desenvolvimento Proximal (ZDP) de Vigotski (2008), quando o aprendiz ainda não consolidou um saber por completo, porém é capaz de utilizá-lo com auxílio externo. Os jogos podem, portanto, ser muito eficientes no Ensino quando trabalhados na ZDP, pois apresentam um desafio próximo, mas além das atuais habilidades dos educandos, instigando-os a encontrar meios para superá-lo e a construir conhecimentos nesse processo.

Contudo, é natural que, nesse processo de tentativa de superação dos desafios, erros e fracassos ocorram. Resta buscar compreender, portanto, qual a relação entre esses resultados insatisfatórios, a diversão e a motivação para se continuar jogando e, em consequência, seus impactos em processos de ensino e de aprendizagem.

\section{O fracasso nos jogos digitais}

Em um primeiro momento, apresentar um grande desafio para um jogador pode parecer um contrassenso: é muito provável que, na tentativa de superar o desafio proposto, o jogador falhe, e o senso comum diria que esse jogador se sentiria desmotivado a continuar, pois ninguém gosta de falhar. Porém, se os bons jogos são aqueles que apresentam grandes desafios, aumentando a proporção de derrotas, como explicar esta relação entre desafio, insucessos e motivação?

Juul (2013) buscou explorar essa questão e apresentou um paradoxo como ponto inicial para a investigação da relação entre esses elementos e prazer, "o paradoxo do fracasso": nós, em geral, evitamos fracassos; nós experimentamos fracassos enquanto jogamos; e nós buscamos os jogos, ainda que experimentemos algo que normalmente evitamos.

Como entender esse paradoxo em relação aos jogos digitais? Resgatar um argumento apresentado acima pode contribuir para essa compreensão: os jogos como problemas a serem resolvidos e o prazer que vem da resolução desses problemas. Um dos motivos apresentados por Juul (2013) para explicar esse comportamento seria uma espécie de aposta que fazemos quando jogamos, considerando que o prazer obtido em superar o desafio - o que McGonigal (2012) chama de fiero - será maior do que o ressentimento causado pelo fracasso.

Contudo, Juul (2013) não se limitou ao campo teórico ao pesquisar esse assunto e obteve interessantes dados empíricos no que concerne às derrotas e à apreciação de um jogo: 85 pessoas jogaram o mesmo jogo e, após essa tarefa, avaliaram-no. Juul (2013) dividiu as respostas obtidas em três grupos, de acordo com o desempenho dos pesquisados - aqueles que não terminaram o jogo, aqueles que terminaram após alguns 
insucessos e aqueles que terminaram sem nenhuma derrota - e, curiosamente, a maior média das notas dadas à qualidade do jogo veio do grupo daqueles que o concluíram após fracassarem algumas vezes. Dessa experiência, podemos inferir que jogadores não gostam de fracassar, mas gostam menos ainda de um jogo que não os leva à derrota ao menos algumas vezes. Da mesma maneira, a pesquisa realizada por Juul (2013) traz indícios de que não somente buscamos os jogos sabendo que encontraremos reveses, mas que preferimos aqueles jogos que nos fazem fracassar algumas vezes antes de chegarmos ao objetivo final.

Dessa pesquisa, temos uma indicação de que fracassar em um jogo, ao contrário do que pode parecer em um primeiro momento, é algo bom, e na verdade aumenta o prazer obtido através dele. Mas por que motivos os jogadores reagem dessa maneira?

Um primeiro aspecto que pode auxiliar na compreensão dessa relação entre os insucessos e o prazer, destacado por uma série de pesquisadores (Gee, 2003; Klopfer, Osterweil; Salen, 2009; Juul, 2013), é a diferença entre o fracasso na vida real e o fracasso nos jogos. E, para compreender essa diferença, é importante compreender a separação que existe entre os jogos e o cotidiano.

Um dos principais argumentos que ajudam a compreender essa diferenciação entre o insucesso nesses dois contextos (e que, em consequência, transforma a derrota no jogo em algo positivo) é o argumento conhecido como "círculo mágico" (Salen; Zimmerman, 2003), com fortes raízes na obra "Homo Ludens" (Huizinga, 2010): o jogo é diferente da vida real; ele é regido por regras específicas que nem sempre valem em outros ambientes e, o mais importante, seus resultados nem sempre possuem consequências tangíveis. Em outras palavras, o que acontece em um jogo não necessariamente gera efeitos em outras esferas da vida. Isso fornece um espaço maior para experimentações e tentativas, para que o jogador procure arriscar mais do que faria caso os resultados obtidos trouxessem consequências reais. É por conta dessa possibilidade de se arriscar sem correr grandes riscos que os jogos muitas vezes são descritos como "espaços seguros" (Gee, 2003), ou ainda que a "liberdade de fracassar" (Klopfer, Osterweil; Salen, 2009) seja celebrada como uma característica comum dos videogames.

Outro aspecto para compreendermos a diferença entre o insucesso nos jogos (em especial nos bons jogos) e na vida real é a clara chance de recuperação que os jogos oferecem. Uma derrota em um videogame não deixa de ser um fracasso, porém o jogador não deve encará-lo como uma situação definitiva, mas sim como algo transitório, como uma nova oportunidade para seguir seus rastros e corrigir - depurar as falhas antes cometidas e superar o desafio proposto. A chance de recuperação é quase imediata e, através dos jogos digitais, podemos lidar com nossas falhas, construindo estratégias para superarmos o problema proposto (Juul, 2013).

O revés nos jogos digitais é como um "remédio amargo": decerto, ninguém gosta de errar, e não são incomuns reações ríspidas a resultados desse tipo. Contudo, ao mesmo tempo, estes resultados indesejados são motivadores e nos fazem refletir sobre as estratégias e pensar em novas saídas.

A partir desse entendimento, é possível compreender porque, na pesquisa de Juul (2013), os jogadores que fracassaram algumas vezes foram aqueles que ofereceram as maiores notas ao jogo. Considerando esses artefatos como problemas a serem resolvidos, e que o prazer por eles proporcionados viria da solução desses problemas de exercitar nosso cérebro aprendendo como solucioná-los, como afirma Koster (2005) -, o fracasso é de certo modo uma maneira de medir o desafio apresentado. Fracassar e 
abandonar um jogo pode significar que o desafio está além da capacidade ou que o jogo não foi bem projetado (em ambos os casos, representa uma frustração para os jogadores). Da mesma maneira, completar um jogo sem um único insucesso significa que o desafio apresentado está aquém de nossas habilidades, gerando nada além de tédio nos jogadores.

Assim, é possível argumentar que os jogos são exemplos de atividades nas quais os fracassos muitas vezes se tornam combustível para que o jogador busque se desenvolver, ao invés de um simples fator que gera desmotivação. Contudo, como destacamos acima, as falhas cometidas durante os jogos devem ser vistas como bugs, como oportunidades para a construção do conhecimento, e não como passíveis de serem punidos. Como, porém, explorar esta relação entre os erros e a aprendizagem?

\section{Jogos, fracassos e Educação}

Integrar jogos e Educação pode ser complexo por uma série de fatores, e o modo como ambos lidam com os fracassos é um deles: como vimos acima, os equívocos e insucessos fazem parte dos jogos (e do prazer de jogar um jogo). Contudo, esse não é o mesmo tratamento que as falhas recebem quando ocorrem no processo educacional: Valente (2005) ressalta como os erros são desencorajados e até mesmo punidos no ensino tradicional.

É importante destacar como esse tipo de resposta, que busca eliminar ou punir as falhas, pode ser prejudicial: Juul (2013) chama a atenção para a incapacidade aprendida como um possível comportamento destrutivo, originado pela interpretação incorreta desses resultados indesejados. Ela aconteceria quando o aluno interpreta sua falha não como um bug - uma situação temporária que ele é capaz de modificar -, mas como um sinal de uma incapacidade própria para realizar certa tarefa, como se o erro ou o fracasso fossem necessariamente definitivos, e ele fosse incapaz de corrigir as inadequações e atingir os resultados desejados por conta de uma suposta falta de habilidade inerente à sua pessoa.

$\mathrm{Na}$ verdade, o aluno deve compreender que não é uma inaptidão natural que o impede de chegar ao resultado adequado, nem que seu insucesso é uma situação definitiva: os resultados inadequados são obtidos por conta de uma abordagem equivocada para solucionar o problema. Da mesma maneira, o aluno deve encarar esse insucesso como um bug e depurar conceitos e estratégias para então melhora-los e, com isso, atingir o resultado esperado.

Assim, é razoável considerar que, em geral, os jogos digitais oferecem uma melhor aproximação aos fracassos que o ensino tradicional. Isso, porém, não significa que os jogos sejam inovadores por completo em relação ao tratamento dos erros: teorias - como as de Vigotski (2008) e de Papert (1985) - que propõem a aprendizagem como a construção do conhecimento através da interação do aluno com o meio já definiam a importância dessa relação, assim como a relevância das falhas cometidas nesse processo para a construção do conhecimento a partir de um ciclo de ações que auxiliam na aprendizagem. Nesse ciclo, o educando age, interpreta os resultados obtidos e depura as estratégias utilizadas anteriormente, até encontrar estratégias satisfatórias, em um processo conhecido como a espiral de aprendizagem (Valente, 2005).

Dessa maneira, deve-se pensar nos jogos como um veículo em que os equívocos cometidos pelos educandos no processo de aprendizagem sejam tratados como bugs, como uma oportunidade para construção do conhecimento, e não como algo a ser 
ignorado, evitado ou punido. Contudo, esta aparente vantagem dos jogos frente ao ensino tradicional, somada a outros fatores (como a motivação e o engajamento) podem fazer com que os jogos sejam tratados como uma panaceia para a Educação, algo que decerto não são. Esse furor frente aos jogos na Educação pode até mesmo levar a escolhas equivocadas na busca da exploração dos potenciais dos jogos no processo educacional.

Um dos principais equívocos que podem ocorrer no que concerne aos jogos digitais e a aprendizagem é utilizá-los apenas como um tipo de reforço behaviorista, apenas recompensando comportamentos considerados positivos e punindo comportamentos considerados negativos. Antes de escolher esse caminho, os jogos devem ser tratados como uma forma cultural, e não como um mero veículo neutro de transmissão de informações e conceitos (Buckingham, 2007). Do mesmo modo, os potenciais educacionais e expressivos dos jogos digitais não estão necessariamente ligados ao ato de jogar ou apenas ao resultado obtido, mas sim na reflexão do jogador sobre o que o levou a obter aquele resultado - como ocorre, por exemplo, no processo de depuração.

Apesar dessa defesa teórica do potencial dos erros para a aprendizagem, seria mesmo o erro um elemento tão útil na Educação? Como explorar o erro de maneira positiva em uma situação pedagógica?

\section{Aprendendo através dos erros na construção de um jogo}

A experiência a seguir relatada ocorreu em uma iniciativa do tipo oficina ocorrida em uma escola pública primária da cidade de Londres (Inglaterra). Nela, utilizamos o software MissionMaker (Burn; Buckingham, 2007) para que alunos da terceira série do ensino fundamental explorassem os jogos, através de sua criação, tanto como meio expressivo quanto como um caminho para o desenvolvimento de habilidades computacionais (De Paula; Valente; Burn, 2014).

No caso aqui citado, trabalhamos com esses alunos em uma sessão de criação de jogos em uma aula regular que durou cerca de 90 minutos. Os alunos utilizaram laptops e a sala foi organizada em diferentes duplas, sendo assim cada dupla responsável pela elaboração de um jogo. Entretanto, ao invés de focarmos nos resultados gerais obtidos nessa experiência, apresentaremos como, em algumas situações, obtivemos o que podem ser considerados indícios do valor dos erros como mecanismos de aprendizagem.

Antes de passarmos propriamente à exemplificação do potencial dos erros, é preciso compreender que a principal dinâmica de criação dentro do programa em questão é combinar os diferentes elementos disponíveis no software (Salas, Personagens, Objetos etc.) e relacioná-los através da simplificada linguagem de programação empregada. Apesar dos erros aparecerem em diferentes momentos, acreditamos que aqueles ocorridos na montagem das regras - a "programação" dentro do MissionMaker - sejam aqueles mais valiosos para exemplificar nosso ponto de vista.

A programação das regras dentro do MissionMaker é executada de maneira simplificada e diferente do usual em ambientes de programação. Primeiramente, é simplificada, pois ela ocorre a partir da seleção das opções fornecidas para o jogador a partir de suas escolhas iniciais; em segundo lugar, é diferente do usual, pois o fluxo é invertido: começa a se estabelecer o comando a partir da consequência, e depois definimos a causa. 
No caso aqui citado, trataremos do exemplo fornecido pela dupla que demonstrou maior capacidade do manejo do MissionMaker: após as primeiras instruções e o exemplo inicial, a dupla em questão já produzia comandos mais complexos envolvendo diferentes tipos de elementos (Personagens e Objetos), enquanto a maioria dos alunos ainda concentrava-se na manipulação de portas através do clique. Os alunos em questão gostariam de produzir uma espécie de "duelo" entre o jogador e um personagem controlado pelo computador. Para isso, disponibilizaram uma arma ao jogador e desejavam que, assim que o jogador coletasse a arma, o inimigo passasse a caçá-lo.

A Figura 1 mostra a primeira tentativa dos alunos de colocarem essa regra em prática. Como é possível ver na imagem em questão, a primeira regra proposta pelos alunos era: "Quando a RayGun1 (arma disponível para o jogador) é clicada, FemaleStormTrooper1 (inimigo) caça o Player (jogador)."

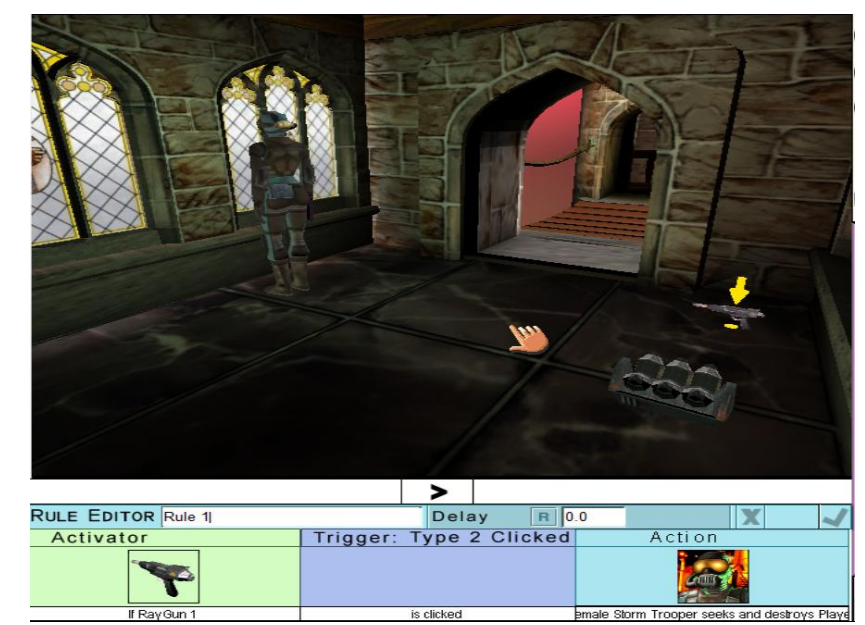

Figura 1 - Primeira tentativa de programação para o duelo

Entretanto, essa primeira versão não apresentou os resultados que os alunos esperavam: o inimigo contava com uma grande vantagem, pois para coletar o objeto, o jogador deveria clicar e arrastar a arma para o inventário, porém, já após o clique o inimigo iniciava o ataque. Com esse fracasso, os alunos pediram auxílio, e buscamos fazê-los refletir sobre como essa regra deveria ser descrita.

Ao explicar sua intenção com a regra, os alunos destacaram que não desejavam que o jogador fosse atacado pelo inimigo até que o jogador coletasse a arma. Nesse sentido, incentivamos então que pensassem sobre a regra que deveriam criar: seria realmente o clique na arma a condição necessária para que o ataque se iniciasse? Eles perceberam que o disparador da ação não deveria ser o clique, mas ainda não sabiam exatamente como poderiam traduzir essa regra para dentro do programa.

Primeiramente, os alunos pensaram que o disparador da ação seria algo do tipo "o jogador coleta a arma", porém após algumas tentativas perceberam que não havia nenhuma opção próxima a essa. Novamente, incentivamos que refletissem sobre o que significa o jogador coletar um objeto, pedindo que pensassem sob outra perspectiva.

A partir dessa palavra, um dos alunos compreendeu o que deveriam modificar: o foco para definir o disparador da ação não deveria ser o jogador, mas sim o objeto (a arma) em questão. Assim, eles não deveriam definir que é o jogador quem coleta o objeto, mas sim o objeto que é coletado pelo jogador. A Figura 2 apresenta essa nova versão da regra, dessa vez funcional como os alunos tinham planejado anteriormente. 
Na parte inferior podemos lê-la: "Se o estado da RayGunl torna-se 'em posse do Player (Jogador)', FemaleStormTrooperl (inimigo) caça o Player (jogador).".

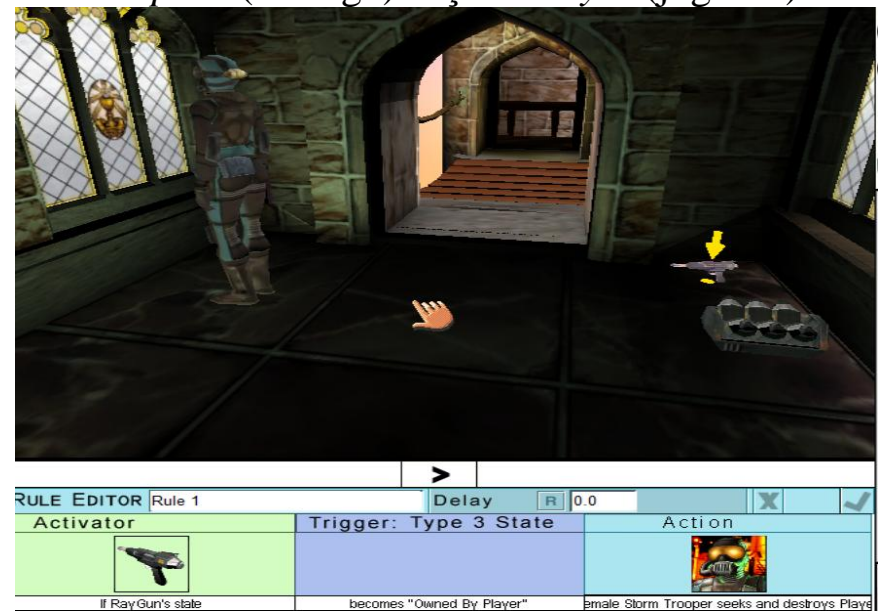

Figura 2 - Regra funcional, após a reflexão sobre o erro cometido anteriormente

Essa situação fez com que os alunos desenvolvessem um conceito importante dentro do contexto da aula em questão: em alguns momentos, na solução de problemas, é preciso buscar diferentes perspectivas para se chegar ao resultado esperado. Após o primeiro fracasso, os alunos até chegaram a pensar em uma solução correta, mas ela não era possível de ser implementada por conta de uma limitação do software; entretanto, foi através desse caminho que eles foram capazes de chegar à solução final, satisfatória.

É preciso destacar ainda outro elemento importante para que os alunos aprendam com os próprios erros: a clareza e velocidade dos feedbacks. Se eles não tivessem percebido claramente que o resultado obtido não era aquele desejado, provavelmente não teriam sido capazes de refletirem e depurar seu código. Da mesma maneira, podemos defender que os rastros deixados pelas tentativas anteriores foram importantes para que pudessem finalmente chegar à solução final desejada. $\mathrm{O}$ fato de deixar rastros e poder depurar o que foi feito é uma importante característica das tecnologias digitais, que devem ser melhor exploradas no processo de ensino e de aprendizagem.

\section{Considerações finais}

Os erros e fracassos mostram-se importantes para a diversão, já que, como mostra Juul (2013), eles são responsáveis pelo engajamento e pela sensação de satisfação do jogador. Entretanto, não podemos nos esquecer do potencial educacional dos erros e dos fracassos, já que eles podem atuar ao mesmo tempo como combustível para que o jogador supere o problema proposto, assim como um recurso para que ele compreenda como pode superá-lo.

A partir dessa visão, foi possível comparar as diferenças entre como o ensino tradicional e os jogos digitais tratam os reveses. Destacamos também que a maneira como os jogos digitais permitem o tratamento dos insucessos está mais próxima de outras teorias educacionais - como as de Vigotski (2008) e Papert (1985) -, em especial aquelas que propõem a construção do conhecimento por parte do educando a partir da interação com seu meio. É importante destacar, também, que tanto Papert (1985) quanto Valente (2005) apresentam a ideia de incentivar os educandos a depurarem os equívocos cometidos no processo educacional como uma forma para se atingir a construção do conhecimento. 
Assim, no contexto da Educação, ao invés de serem ignorados, evitados ou punidos, os fracassos devem ser analisados, tratados como uma importante fonte de informações para a construção do conhecimento. Por esse motivo propomos que sejam analisados como bugs informáticos - deslizes que incomodam, mas passíveis de serem corrigidos a partir de um processo de depuração, em um acompanhamento atento de todas as ações realizadas para encontrar o que causou o erro. A partir desse entendimento, será possível transformar o Ensino em um processo mais significativo, no qual os educandos aprendam a aprender e construam conhecimentos ativamente.

\section{Agradecimentos}

Agradecemos à Fundação de Amparo à Pesquisa do Estado de São Paulo (FAPESP) pelas bolsas concedidas sob os processos 2012/20226-0 (no País) e 2013/19275-0 (Bolsa Estágio de Pesquisa no Exterior), e ao CNPq pela Bolsa Produtividade em Pesquisa, Processo 306416/2007-7.

\section{Referências}

BUCKINGHAM, D. Beyond technology: Children's learning in the Age of Digital Culture. Cambridge: Polity, 2007.

BURN, A.; BUCKINGHAM, D. Game literacy in theory and practice. Journal of Educational Multimedia and Hypermedia, v. 16, n. 3, p.323-349, 2007.

CAPERTON, I. For Seymour Papert "hard fun" is the essence of good games AND good education. Telemedium: the journal of media literacy, v. 52, p. 16-19, 2005.

DE PAULA, B. H.; VALENTE, J. A.; BURN, A. O uso de jogos digitais para o desenvolvimento do currículo para a Educação Computacional na Inglaterra. Currículo sem Fronteiras, v. 14, n.3, p.46-71, set/dez 2014.

EGENFELDT-NIELSEN, S.; SMITH, J. H.; TOSCA, S. P. Understanding video games: the essential introduction. Nova York: Routledge, 2008.

GEE, J. P. What video games have to teach us about learning and literacy. Nova York: Palgrave-Macmillan, 2003.

HUNICKE, R.; LEBLANC, M.; ZUBEK, R. MDA: A formal approach to game design and game research. Proceedings of the AAAI Workshop on Challenges in Game AI, jul-2004.

HUIZINGA, J. Homo ludens: o jogo como elemento da cultura. São Paulo: Perspectiva, 6 ${ }^{\mathrm{a}} \mathrm{Ed}, 2010$.

JUUL, J. The art of failure: an essay on the pain of playing video games. Cambridge: MIT Press, 2013. [E-book].

KLOPFER, E.; OSTERWEIL, S.; SALEN, K. Moving learning games forward. Cambridge: The Education Arcade, 2009.

KOSTER, R. A theory of fun for game design. Scottsdale: Paraglyph Press, 2005.

MCGONIGAL, J. A realidade em jogo: porque os games nos tornam melhores e como eles podem mudar o mundo. Rio de Janeiro: Best-Seller, 2012.

PAPERT, S. Logo: Computadores e Educação. São Paulo: Brasiliense, 1985.

SALEN, K.; ZIMMERMAN, E. Rules of Play: Game Design Fundamentals. Cambridge: MIT Press, 2003.

SQUIRE, K. Videogames and learning: teaching and participatory culture in digital age. Nova York: Teachers College Press, 2011. 
VALENTE, J. A. Depurar. In FAZENDA, I. (org.). Dicionário em construção: Interdisciplinaridade. São Paulo: Editora Cortez, 2001.

VALENTE, J. A. A espiral da espiral de aprendizagem: o processo de compreensão do papel das tecnologias de informação e comunicação na educação. 2005, Tese (Livre Docência em Multimeios e Ciência), Universidade Estadual de Campinas, Instituto de Artes, Campinas, SP.

VIGOTSKI, L. S. A formação social da mente. São Paulo: Martins Fontes, 2008. 